\section{Meningococcal Disease in an International Traveler on Eculizumab Therapy — United States, 2015}

Allen O. Applegate, DrPH ${ }^{1}$; Vanessa C. Fong, $\mathrm{MPH}^{1}$; Kara Tardivel, $\mathrm{MD}^{1}$; Susan A. Lippold, $\mathrm{MD}^{1}$; Sheilah Zarate, $\mathrm{MSN}^{2}$

On June 2, 2015, CDC was notified that a male airline passenger, aged 41 years, with a fever of $105.4^{\circ} \mathrm{F}$, headache, nausea, photophobia, diarrhea, and vomiting, which began approximately 3 hours after departure, was arriving to San Francisco, California, on a flight from Frankfurt, Germany. His symptoms reportedly started with neck stiffness 1 day earlier. Upon arrival, the patient was immediately transported to a local hospital, where he was in septic shock, which was followed by multisystem organ failure. cerebrospinal fluid, obtained approximately 12 hours after initiation of treatment, was Gram stain- and culture-negative. Blood cultures, which were drawn before antibiotic treatment, were positive for Neisseria meningitides of indeterminate serogroup. A review of the patient's medical records revealed a history of paroxysmal nocturnal hemoglobinuria and current biweekly eculizumab (Soliris) therapy.

In 2007, eculizumab became the first Food and Drug Administration (FDA)-approved therapy for paroxysmal nocturnal hemoglobinuria, a rare type of autoimmune hemolytic anemia (1). Eculizumab is a monoclonal antibody that inhibits activation of the complement system, thus rendering patients vulnerable to infection with encapsulated organisms such as $N$. meningitidis $(1,2)$. Eculizumab carries a FDA black box warning about meningococcal infections, with the recommendation that patients receive quadrivalent meningococcal conjugate vaccine at least 2 weeks before starting eculizumab therapy and a booster dose every 5 years thereafter $(3,4)$. This patient received quadrivalent meningococcal polysaccharide vaccine in 2012, before beginning therapy.

On the basis of the patient's history of eculizumab therapy, CDC initiated an aviation contact investigation for suspected meningococcal disease before receiving laboratory confirmation. Current CDC guidelines for meningoccal disease recommend that on flights of $\geq 8$ hours duration, passengers seated on either side of the patient and any crew with close contact to the patient receive postexposure prophylaxis (3). To identify passenger contacts, CDC obtained the airline passenger manifest and customs declaration forms for the flight. Interviews with responding paramedics and cabin crew also identified two unnamed medical volunteers on the flight: a nurse and a paramedic. Using the limited information provided (physical description, professions, and traveling companions) CDC was able to identify the medical volunteers through crossreferencing manifest information with the California Department of Consumer Affairs License Verification page and photos associated with electronic customs declarations forms. Six conveyance contacts were identified (one passenger, two medical volunteers, and three flight $\mathrm{crew}$ ); five received postexposure prophylaxis within 48 hours of the flight and one declined. In addition, two responding paramedics who were initially not wearing masks and two laboratory technicians at the treating hospital received postexposure prophylaxis. After intravenous antibiotic treatment, the patient recovered fully.

Although evidence is limited for the risk for in-flight $N$. meningitidis transmission, there are at least two documented instances of probable transmission, including a case on a commercial flight from Los Angeles to Sydney, Australia in 2003 (5) and a cluster associated with a charter flight in 2005 (6). When meningococcal disease is suspected in an air traveler, close coordination with federal, state, local, and private sector partners is critical to obtain contact information for persons with potential exposure to the patient to ensure their rapid postexposure prophylaxis and, thus, prevent additional cases. This case also highlights the importance of heightened clinical suspicion for meningococcal disease in patients on eculizumab therapy, regardless of vaccination history.

\section{Acknowledgments}

Jessica MacNeil, Manisha Patel, CDC; Susan Dwyer, CDC San Francisco Quarantine Station; Denise Borntrager, CDC San Diego Quarantine Station; Kathleen Harriman, Kathleen Winter, California Department of Public Health; Cynthia Amezcua, San Mateo County Health Services, California; Becky Riemer, Sutter Health, Mills-Peninsula Medical Center, Burlingame, California; Danielle Womack, Dr. Eric McDonald, San Diego County Public Health Services.

\footnotetext{
${ }^{1}$ Division of Global Migration and Quarantine, National Center for Emerging and Zoonotic Infectious Diseases, CDC; ${ }^{2}$ San Francisco Department of Public Health.

Corresponding author: Kara Tardivel, wjf3@cdc.gov, 310-215-2365.
} 


\section{References}

1. Dmytrijuk A, Robie-Suh K, Cohen MH, Rieves D, Weiss K, Pazdur R. FDA report: eculizumab (Soliris) for the treatment of patients with paroxysmal nocturnal hemoglobinuria. Oncologist 2008;13:9931000. http://dx.doi.org/10.1634/theoncologist.2008-0086

2. Hillmen P, Muus P, Röth A, et al. Long-term safety and efficacy of sustained eculizumab treatment in patients with paroxysmal nocturnal haemoglobinuria. Br J Haematol 2013;162:62-73. http://dx.doi. org/10.1111/bjh.12347

3. CDC. Meningococcal: who needs to be vaccinated? Atlanta, GA: US Department of Health and Human Services, CDC; 2015. http://www. cdc.gov/vaccines/vpd-vac/mening/who-vaccinate.htm
4. CDC. Prevention and control of meningococcal disease: recommendations of the advisory committee on immunization practices (ACIP). Atlanta, GA: US Department of Health and Human Services, CDC; 2015. http:// www.cdc.gov $/ \mathrm{mmwr} /$ preview $/ \mathrm{mmwrhtml} / \mathrm{rr} 6202 \mathrm{a} 1 . \mathrm{htm}$

5. O'Connor BA, Chant KG, Binotto E, Maidment CA, Maywood P, McAnulty JM. Meningococcal disease-probable transmission during an international flight. Commun Dis Intell Q Rep 2005;29:312-4.

6. Riley LK. Bacterial meningitis exposure during an international flight: lessons for communicable pathogens. Aviat Space Environ Med 2006;77:758-60 